\title{
Evaluation of The Use of a Cloverleaf Plate as a Sacroiliac Joint Plate for Treating Complex Sacroiliac Joint Injuries
}

\author{
Winson Low Min Teng ${ }^{1}$, Yung Heng $\mathrm{Hsu}^{2}$, Ying Chao $\mathrm{Chou}^{3}$ and Yi Hsun $\mathrm{Yu}^{4 *}$ \\ ${ }^{1}$ Department of Orthopedic Surgery, Musculoskeletal Research Center, Chang Gung Memorial Hospital, Taiwan \\ ${ }^{2}$ Department of Orthopedic Surgery, Musculoskeletal Research Center, Chang Gung Memorial Hospital, Taiwan \\ ${ }^{3}$ Department of Orthopedic Surgery, Musculoskeletal Research Center, Chang Gung Memorial Hospital, and Department of Mechanical Engineering, Chang \\ Gung University, Taiwan \\ ${ }^{4}$ Department of Orthopedic Surgery, Musculoskeletal Research Center, Chang Gung Memorial Hospital, Taiwan
}

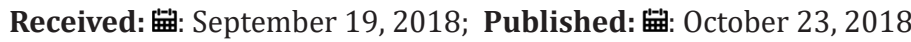

*Corresponding author: Yi Hsun Yu, Division of Orthopedic Traumatology, Department of Orthopedic Surgery, Musculoskeletal Research Center, Chang Gung Memorial Hospital and Chang Gung University, 5, Fu-Hsin St, Kweishan, 33302, Tao-Yuan, Taiwan

Abstract

Background: Various fixation methods can be applied in sacroiliac injuries.

Objective: To propose an alternative fixation method for sacroiliac joint injuries with a pre-contoured cloverleaf plate.

Methods: We used a modified surgical technique with using a cloverleaf plate as a sacroiliac joint plate for treating a series of 7 patients with complex sacroiliac joint injuries in a single medical institute. The surgical technique was detailed described. Each patient was followed up with at the outpatient clinic after discharge at 2 weeks, 4 weeks, 12 weeks, and until bone union and pelvic ring stabilization.

Results: All patients were followed up with for at least 6 months. There were no perioperative complications, such as nerve or vascular injury, a broken plate, loose screw and plate, and loss of reduction, due to the osteosynthesis operations. During the follow-up period, all fixations were maintained until early bone union.

Conclusion: Fixation of a sacroiliac joint fracture with a cloverleaf plate is an alternative and new option that provides good fixation strength and economic efficiency.

Keywords: Sacroiliac Joint; Radiography; Surgical Technique; Cloverleaf Plate

\section{Introduction}

Sacroiliac joint injury is a common injury caused by highenergy trauma and it is associated with unstable pelvic ring injury [1-3]. This injury pattern causes rotational instability of the hemipelvis, and osteosynthesis operation with internal fixation is always necessary to restore posterior pelvic ring stability [4]. The options of fixation for sacroiliac joints include iliosacral (transiliac/trans-sacral) screw by closed or open reduction $[2,3,5,6]$, open reduction and internal fixation with two orthogonal plates ventrally [4], and even triangular osteosynthesis for more complex and vertically unstable fractures $[7,8]$. The choice of fixation should be individualized according the type of pelvic injury. In the present report, we propose a technical modification whereby the stability from fixation can be improved easily without surgeons having to resort to using multiple plates. By using a cloverleaf plate to stabilize the sacroiliac joint, the area of contact is broadened and acts as a single implant. We describe the use of this technique in our small case series of 7 patients.

\section{Materials and Methods}

Under the approval of Institutional Reviewing Board, we reviewed patients with fracture or fracture dislocation of the sacroiliac joint between March 2016 and December in 2016. During this study period, we performed a modified surgical technique on 7 patients whose demographic data and fracture classification are listed in Table 1. Each patient was followed up with at the outpatient clinic after discharge at 2 weeks, 4 weeks, 12 weeks, and until bone union and pelvic ring stabilization. 
Table 1: Demographic data of the 7 patients.

\begin{tabular}{|c|c|c|c|c|c|c|c|c|c|}
\hline $\begin{array}{c}\text { Patient } \\
\text { no. }\end{array}$ & Sex & Age (years) & $\begin{array}{c}\text { Traumatic } \\
\text { mechanism } \\
\text { of injury }\end{array}$ & Associated injuries & $\begin{array}{c}\text { Injury } \\
\text { severity score }\end{array}$ & $\begin{array}{c}\text { Fracture } \\
\text { classification\# }\end{array}$ & $\begin{array}{l}\text { Duration of } \\
\text { operation } \\
\text { (h) }\end{array}$ & $\begin{array}{c}\text { Estimated } \\
\text { blood loss } \\
(\mathrm{mL})\end{array}$ & $\begin{array}{l}\text { Correction } \\
\quad \text { of } \\
\text { rotational } \\
\text { deformity } \\
(\%)^{*}\end{array}$ \\
\hline 1 & $\mathrm{~F}$ & 53 & $\begin{array}{l}\text { Motorbike } \\
\text { crash }\end{array}$ & $\begin{array}{l}\text { 1. Rib fractures } \\
\text { with bilateral } \\
\text { hemopneumothorax } \\
\text { 2. Liver laceration, } \\
\text { grade III } \\
\text { 3. Radius and ulna } \\
\text { fracture }\end{array}$ & 34 & 61-B3.2 & 2 & 50 & 0 \\
\hline 2 & $\mathrm{~F}$ & 21 & $\begin{array}{l}\text { Motorbike } \\
\text { crash }\end{array}$ & $\begin{array}{l}\text { 1. Kidney laceration } \\
\text { grade I } \\
\begin{array}{l}\text { 2. Nasal bone } \\
\text { fracture }\end{array}\end{array}$ & 20 & 61-B3.2 & 3 & 150 & +19.0 \\
\hline 3 & $\mathrm{~F}$ & 71 & $\begin{array}{l}\text { Pedestrian } \\
\text { struck }\end{array}$ & Nil & 9 & 61-B2.2 & 3 & 350 & -11.7 \\
\hline 4 & M & 56 & $\begin{array}{l}\text { Motorbike } \\
\text { crash }\end{array}$ & Nil & 9 & 61-B1.2 & 3 & 800 & -3.0 \\
\hline 5 & $\mathrm{~F}$ & 39 & $\begin{array}{l}\text { Motorbike } \\
\text { crash }\end{array}$ & $\begin{array}{l}\text { 1. Rib fractures } \\
\text { 2. Cardiac contusion } \\
\begin{array}{c}\text { 3. Thoracic spine } \\
\text { fracture }\end{array}\end{array}$ & 38 & 61-B3.2 & 3 & 300 & +11.7 \\
\hline 6 & $\mathrm{~F}$ & 29 & $\begin{array}{l}\text { Motorbike } \\
\text { crash }\end{array}$ & $\begin{array}{l}\text { 1. Hepatic laceration } \\
\text { grade I. } \\
\text { 2. Splenic laceration, } \\
\text { grade II }\end{array}$ & 13 & 61-B2.2 & 4 & 600 & -6.7 \\
\hline 7 & M & 53 & Crush injury & $\begin{array}{l}\text { 1. Rib fractures } \\
\text { with pulmonary } \\
\text { contusion } \\
\text { 2. Sternal fracture }\end{array}$ & 25 & $61-3.2$ & 4 & 1300 & +5.6 \\
\hline
\end{tabular}

\section{Surgical Technique}

This technique is indicated for patients with pelvic fractures involving an injury to the sacroiliac joint. We used a conventional cloverleaf plate (Depuy Synthes, West Chester, PA, USA) as the fixation implant for such an injury (Figure 1A). The plate can be sized and pre-contoured by removing the stem part and leaving only the leaf part (Figure 1B). The leaf portion can be bent, and the remainder stem part of the plate can be gently twisted to match the contour of the sacrum, sacroiliac joint, and ileum (Figure 1C). The screws that go through the leaf part and into the sacrum can be tailored, mainly depending on the injury pattern, and usually 2 to 3 screws are necessary (Figure 1D). The plate can be slightly over-bent at the junction of the leaf part and stem part to overcome the external deformity of the injured hemipelvis. The remaining stem part of the plate should be twisted to fit the anatomical ileum surface. 

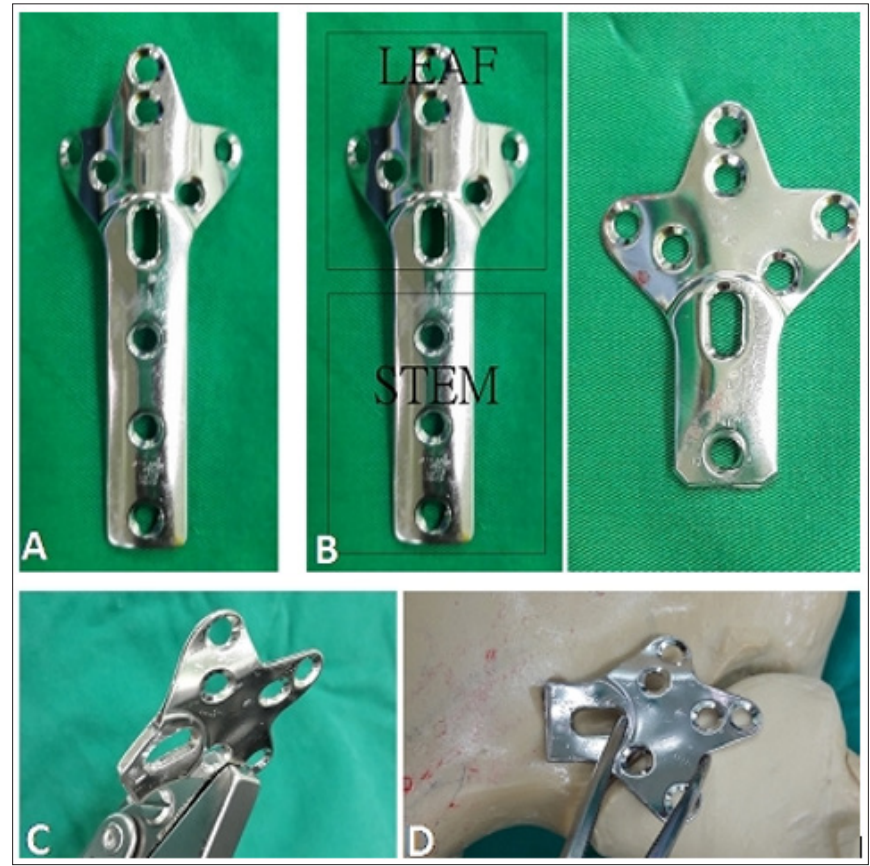

Figure 1: (A) A conventional cloverleaf plate. (B) The cloverleaf plate is divided into a leaf part and a stem part. The stem part can be contoured by removing two or three holes. (C) The plate can be contoured according to different types of fractures. (D) Application of a pre-contoured plate onto the sacroiliac joint.

A screw can be used to fix the plate and posterior superior iliac crest at the most cranial hole of the leaf part, and another screw can be placed in the hole of the stem part for the ileum. Sometimes two holes of the stem part can be retained for a more complex fracture pattern of the sacroiliac joint. Similar with any one-third plate for a sacroiliac joint injury, surgeons should be careful to ensure that the plates are not placed too medially from the sacroiliac joint, as this may cause irritation and injury to the L 5 nerve root. Other potential complications associated with this plate include nonanatomical reduction of the sacrum and ileum due to over-contouring or undercontouring, and improper reduction of the ventral pelvic ring and placement of the ventral pelvic ring plate if the plate is too bulky. The cloverleaf plate for a sacroiliac joint injury is always positioned through the lateral surgical window, either using the ilioinguinal approach or an isolated incision combined with the modified Stoppa approach. After reduction and fixation of the sacroiliac joint injury, the rest of the fractured pelvis can be reduced and fixed in a step-by-step manner.

\section{Results}

All patients were followed up with for at least 12 months. There were no perioperative complications, such as nerve or vascular injury, a broken plate, loose screw and plate, and loss of reduction, due to the osteosynthesis operations. During the follow-up period, all fixation was maintained until early bone union (Figure 2A \& 2C). All patients followed the tailor-made rehabilitation protocol according to the severity of their injuries.
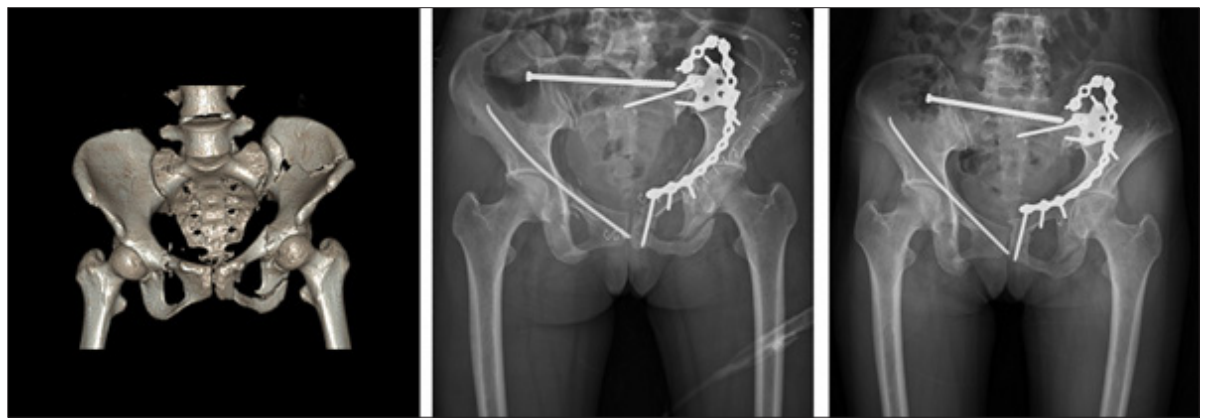

Figure 2: Presentation of case number 5, a 38-year-old woman who was involved in a traffic crash (motorbike versus truck). (A) A 3-dimensional computed tomography scan of the pelvis showing a pelvic fracture (AO/OTA 61-B3.2). (B) Osteosynthesis operation for the pelvic fracture is performed using several implants, including a pre-countered sacroiliac plate. (C) The pelvis is stable at the 12-month follow-up. 


\section{Discussion}

Although fixation of the sacroiliac joint with trans-iliac or trans-sacral screws provides the advantage of less invasiveness, which is the main trend for treating this type of injury, multiplanar sacroiliac joint injury requires open reduction with internal fixation. Our method of using a conventional cloverleaf plate is an alternative method that provided strong construct stiffness for fracture fixation. Fixation with a cloverleaf plate offers a larger contact surface between the plate and bone, and the cost of a cloverleaf plate is affordable. The main limitation of this study was the lack of a biomechanical test to evaluate the exact fixation strength of using a cloverleaf plate to fixate a sacroiliac joint injury. Additionally, there were no comparative data between the standard two separate one-third plates and a commercialized locking plate for treating a sacroiliac joint injury. Since this technique has not been previously reported, we described our experience, and we think it is a reasonable adjunct for stabilizing the sacroiliac joint. We also believe that a one-piece multi-direction cloverleaf plate for a sacroiliac joint injury can provide better stabilization for fracture healing.

\section{Conclusion}

Fixation of a sacroiliac joint fracture with a cloverleaf plate is an alternative and new option that provides good fixation strength and economic efficiency.

ISSN: 2574-1241

DOI: $10.26717 / B J S T R .2018 .10 .001928$

Yi Hsun Yu. Biomed J Sci \& Tech Res

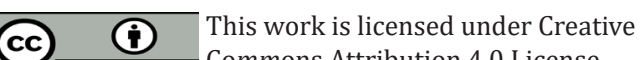

Submission Link: https://biomedres.us/submit-manuscript.php

\section{References}

1. Matta JM, Saucedo T (1989) Internal fixation of pelvic ring fractures. Clin Orthop Relat Res 242: 83-87.

2. Routt ML Jr, Simonian PT, Agnew SG, Mann FA (1996) Radiographic recognition of the sacral alar slope for optimal placement of iliosacral screws: a cadaveric and clinical study. J Orthop Trauma 10: 171-177.

3. Starr AJ, Walter JC, Harris RW, Reinert CM, Jones AL (2002) Percutaneous screw fixation of fractures of the iliac wing and fracture-dislocations of the sacro-iliac joint (OTA Types 61-B2.2 and 61-B2.3, or Young-Burgess "lateral compression type II" pelvic fractures). J Orthop Trauma 16: 116123.

4. Tile M (1996) Acute pelvic fractures I. Causation and classification. J Am Assoc Orthop Surg 4: 143-151.

5. Gardner MJ, Routt ML Jr (2011) Transiliac-transsacral screws for posterior pelvic stabilization. J Orthop Trauma 25: 378-384.

6. Routt ML Jr, Simonian PT, Mills WJ (1997) Iliosacral screw fixation: early complications of the percutaneous technique. J Orthop Trauma 11: 584589.

7. Sagi HC, Militano U, Caron T, Lindvall E (2009) A comprehensive analysis with minimum 1-year follow-up of vertically unstable transforaminal sacral fractures treated with triangular osteosynthesis. J Orthop Trauma 23: 313-319.

8. Schildhauer TA, Josten C, Muhr G (2006) Triangular osteosynthesis of vertically unstable sacrum fractures: a new concept allowing early weight-bearing. J Orthop Trauma 20: S44-S51.

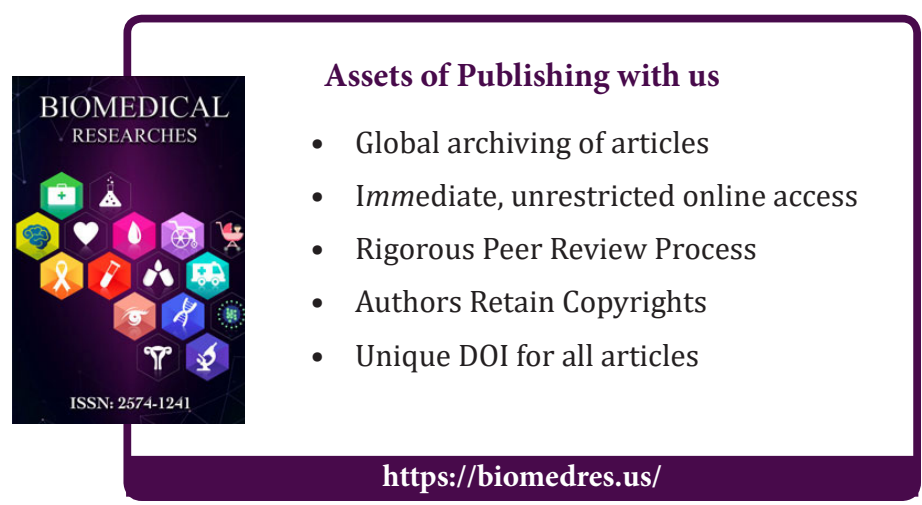

